\title{
Traumatic intermuscular hernia in the anterior abdominal wall
}

\author{
P. S. V. RAO \& B. M. L. KAPUR
}

Department of Surgery, All-India Institute of Medical Sciences, New Delhi, India

\section{SUMMARY}

Traumatic ventral herniae are uncommon. The authors present a patient with traumatic intermuscular hernia in the anterior abdominal wall. Early recognition and differentiation from haematoma is important. In this case, the overlying intact muscle layer masked the classical clinical signs. The incision should be adequate and all internal organs carefully examined. Primary repair is usually possible.

\section{INTRODUCTION}

Anterior abdominal wall hernia following blunt abdominal injury is rare. Only 48 cases, including the 16 cases reviewed by Clain (1964), have been reported in the English literature so far (Astarita \& Brief, 1983). In all these cases, herniation was into the subcutaneous plane or the inguinal canal. This is the first report of a traumatic intermuscular hernia in the anterior abdominal wall.

\section{CASE REPORT}

A 22-year-old male was brought to the casualty department $2 \mathrm{~h}$ after a road traffic accident. His scooter had skidded, impaling him against the handle bar. A swelling had appeared at the site of injury in the left upper abdomen and had progressively increased in size.

A $10 \times 8 \mathrm{~cm}$ swelling was present in the left upper abdomen, extending over the left costal margin. The skin over it was abraded and bruised. It was tender, soft and was thought to be a haematoma. There was guarding in the left upper abdomen. The left flank was dull to percussion. His vital signs were normal and there were no other injuries.

Correspondence: Dr B. M. L. Kapur, Department of Surgery, All-India Institute of Medical Sciences, New Delhi 110029 , India. 
A peritoneal aspiration on the left side yielded frank blood. A chest X-ray revealed fractures of the left ninth and tenth ribs. A diagnosis of splenic injury was made.

The abdomen was explored through an upper midline incision. There was a left- 응 sided haemoperitoneum and a long tear along the left costal margin from the ninth $\overrightarrow{\vec{F}}$ costal cartilage to the tip of the twelfth rib, due to avulsion of the transverses abdominis $\stackrel{9}{\circ}$ and internal oblique muscles from the costal attachment. The torn edges were actively $\frac{c}{0}$ bleeding. The transverse colon and jejunal loops had herniated through this tear into a $\frac{\bar{m}}{5}$ space between the external and internal oblique muscles. There were multiple serosal $\stackrel{\triangleright}{\circledR}$ tears in the transverse, descending and sigmoid colon. The diaphragm, spleen and other organs were intact. The hernia contents were replaced and the serosal tears were $\vec{\circ}$ oversewn. The tear extended too far posteriorly to be sutured from inside through a $\overrightarrow{\vec{\omega}}$ midline incision and a separate incision was made over the defect. The edges were $\stackrel{\omega}{\omega}$ debrided and the defect closed in layers. Post-operative recovery was uneventful and $\frac{\mathbb{D}}{3}$ the patient was discharged 6 days later. On examination, one year later, there was no recurrence of the hernia.

\section{DISCUSSION}

Traumatic abdominal wall hernia usually follows localized blunt trauma, from objects neither small enough to penetrate the skin nor large enough for the force involved to be $\underset{\mathbb{D}}{\overparen{D}}$ dissipated widely (Clain, 1964). Occasionally, disruption of the abdominal wall may $\vec{P}$ result from a severe compressive force (Fullerton et al., 1984) and is associated witi other internal injuries. Raised intra-abdominal pressure is more likely to cause diaphragmatic hernia and this may coexist with a traumatic abdominal wall hernia (Daoud et al., 1978). (Payne et al., 1973). Traumatic lumbar hernia (Everett, 1973; 긍

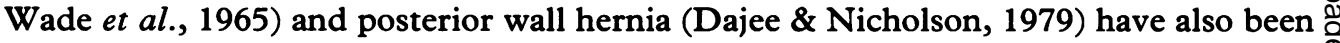
reported, but these are exceedingly rare.

In this patient, the transversalis and internal oblique muscles had been avulsed from $\overrightarrow{\vec{\sigma}}$ the costal margin. The external oblique muscle had withstood the blow, probably $\exists$ because of its higher origin from the external surfaces of the lower eight ribs. Its high origin also allowed the hernia to override the costal margin. The intact external oblique $\stackrel{\bar{\Phi}}{\circ}$ masked the characteristic hernial features of a transmitted cough impulse and visible 3 peristalsis.

The hernia was pre-operatively mistaken for a haematoma in the abdominal wall. In five reported cases (Dubois \& Freeman, 1981; Everett, 1973; Guly \& Stewart, 1983; Kaude, 1966; Moses \& Swartley, 1965), the swelling was initially mistaken for a haematoma and it was incised in two (Dubois et al., 1981; Everett, 1973). Traumatic hernia should also be differentiated from a pre-existing hernia or a tumour in the abdominal wall. Lateral or oblique radiographs (Chabra et al., 1976; Kaude, 1966; \& N Tiwary, 1985), barium studies (Chabra et al., 1976), sonography (Guly \& Stewart, N 1983; Malangoni \& Condon, 1983) and CT scan (Malangoni \& Condon, 1983) may help స్ట in diagnosis. If unrecognized and left untreated, the herniated bowel may obstruct or 0 even strangulate (Hurwitt \& Silver, 1965; Moses \& Swartley, 1965). Late repair has

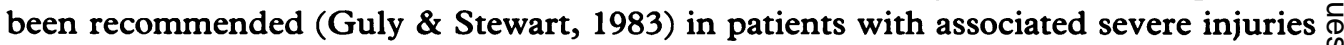
and local skin sepsis. Artificial grafts may be necessary in patients presenting late with a large defect (Martinez et al., 1976). 


\section{REFERENCES}

Astarita D. \& Brief D. K. (1983) Traumatic rupture of the abdominal wall without evisceration. fournal of the Medical Society N.J. 80, 1027-9.

Chhabra H. L., Sarin N. K. \& Khurana S. (1976) Subcutaneous herniation of gut following blunt abdominal trauma (a case report). Indian Paediatrics 13, 469-70.

Clain A. (1964) Traumatic hernia. British fournal of Surgery 51, 549-50

Dajee H. \& Nicholson D. M. (1979) Traumatic abdominal hernia. fournal of Trauma 19, 710-11.

Daoud I. M., Calderelli R. A., Knight H. F. \& Mannix H. Jr (1978) Traumatic diaphragmatic herniation with abdominal wall rupture. Connecticut Medicine 42, 83-5.

Dubois P. M. \& Freeman J. B. (1981) Traumatic abdominal wall hernia. fournal of Trauma 21, 72-4.

Everett W. G. (1973) Traumatic lumbar hernia. Injury 4, 354-6.

Fullerton J. C., Saltzstein E. C. \& Peacock J. B. (1984) Traumatic hernia of the anterior abdominal wall. fournal of Emergency Medicine 1, 213-17.

Guly H. R. \& Stewart I. P. (1983) Traumatic hernia. fournal of Trauma 23, 250-2.

Hurwitt E. S. \& Silver C. E. (1965) A ventral hernia following an automobile crash. fournal of the American Medical Association 194, 829-31.

Kaude J. (1966) Traumatic rupture of the abdominal wall with subcutaneous herniation of the transverse colon and perforation of the small bowel. British fournal of Radiology 39, 950-1.

Malangoni M. A. \& Condon R. E. (1983) Traumatic abdominal wall hernia. fournal of Trauma 23, 356-7.

Martinez B. D., Stubbe N. \& Rakower S. R. (1976) Delayed appearance of a traumatic ventral hernia: a case report. fournal of Trauma 16, 242-3.

Moses M.L. \& Swartley R.N. (1965) Subcutaneous rupture of the rectus abdominis muscle with incarcerated hernia and bowel obstruction. American fournal of Surgery 110, 958-9.

Payne D.D., Resnicoff S. A., States J. D. (1973) Seat-belt abdominal wall muscular avulsion. fournal of Trauma 13, 262-7.

Tiwary R. N. \& Tiwary A. K. (1985 Traumatic ventral hernia. Indian fournal of Surgery 47, 465-7.

Wade P, Frey C \& Lampe E (1965) Traumatic retro peritoneal hematoma followed by anuria and lumbar hernia. American fournal of Surgery 109, 253-9. 